\title{
Trust, Continuity and Agency: Keys to Understanding Older Patients' Attitudes to General Practice Trainees
}

\author{
Andrew Bonney ${ }^{1}$, Sandra C Jones' ${ }^{2}$ Don Iverson ${ }^{3}$, Christopher Magee ${ }^{4}$ \\ ${ }^{1}$ Roberta Williams Chair of General Practice, School of Medicine, ${ }^{2}$ Director, ${ }^{4}$ Deputy Director, Centre for Health Initiatives, ${ }^{3}$ Executive Dean, \\ Faculty of Health, Arts and Design Swinburne University of Technology, University of Wollongong, Wollongong, Australia
}

\begin{abstract}
Background: Populations are ageing and therefore non-communicable diseases are becoming leading causes of global morbidity, which need to be the focus of primary care services and training. Some older patients are uncomfortable with general practitioner (GP) trainees managing their chronic conditions, reducing clinical experience opportunities for trainees. This Australian cross-sectional study explored the factors underlying patients' attitudes to trainees in an agency theory framework. Methods: Fifty patients aged 60 and over from each of 38 training practices were offered a questionnaire after their consultation. Principal component analysis of the results was undertaken. Factor scores were calculated. Binary logistic modelling was used to identify relationships between participant characteristics, behaviours, attitude items and factor scores. Results: The response rate was $47.9 \%(n=911)$. Three factors were identified: 'Interpersonal Trust' (IPT); 'Institution/system Trust' (ST); and 'Interpersonal Continuity' (IPC). Lower self-rated health (SRH) was associated with higher IPT factor scores $(P=0.023)$; higher SRH with higher ST scores $(P=0.001)$; and chronic illness with higher IPC scores $(P=0.005)$. Higher ST scores were associated with greater comfort with trainees' involvement in chronic care $(P<0.001)$ and frequency of trainee visits $(P<0.001)$, while higher IPC scores were negatively associated $(P<0.001$ and $P=0.003$, respectively). High IPT scores were associated with lower satisfaction with trainee visits $(P=0.001)$. Discussion: These results indicate that better SRH, via higher institution/ST, is associated with favourable attitudes and attendance with trainees. In addition, chronic illness, via a higher need for IPC, is associated with lower comfort and attendance. These findings are consistent with agency theory, which shows potential as a framework for future interventions and research into older patient-trainee interactions.
\end{abstract}

Keywords: Agency theory, factor analysis, general practice training

\section{Background}

It is well recognised that populations worldwide are ageing ${ }^{[1]}$ and that chronic diseases are becoming the leading causes of morbidity globally. ${ }^{[2]}$ Primary care services are under significant pressure to reorient to the needs of ageing communities and the resultant burgeoning in chronic disease management, ${ }^{[3]}$ with added impetus for reform coming from national ${ }^{[4]}$ and World Health Organisation recommendations. ${ }^{[5]}$ For general

\begin{tabular}{|l|l|}
\hline \multicolumn{2}{|c|}{ Access this article online } \\
\hline Quick Response Code: & Website: \\
\hline & www.educationforhealth.net \\
\cline { 2 - 2 } & \\
\hline
\end{tabular}

practices engaged in training, an ageing population creates a further challenge, which is the imperative to provide future general practitioners (GPs) with appropriate experience in the management of older patients and patients with chronic illnesses. ${ }^{[6]}$

These are considerable challenges, as there is mounting evidence that while older patients are generally willing to consult trainees for minor problems, they are significantly less comfortable in having GP trainees (termed GP registrars in Australia and the United Kingdom) manage chronic conditions. ${ }^{[7-9]}$ This is reflected in the Australian experience that trainees see fewer older and chronically ill patients than established GPs, ${ }^{[6]}$ which may adversely affect the ability of training practices to provide appropriate clinical experience for trainees and reduce the overall chronic disease management capacity of training practices. On a more fundamental level, it also demonstrates

Address for correspondence:

Prof. Andrew Bonney, School of Medicine, University of Wollongong, Wollongong 2522, Australia. E-mail: abonney@uow.edu.au 
[Downloaded free from http://www.educationforhealth.net on Thursday, June 12, 2014, IP: 130.130.37.85] || Click here to download free Android application for this journal

a mismatch between the teaching responsibilities of training practices and the expectations of patients seeking care there.

Older patients and those with chronic conditions require more continuity of care ${ }^{[10]}$ and this is thought to be a key driver of their reluctance to consult trainees ${ }^{[9]}$ While there has been empirical work on patients' attitudes, ${ }^{[9,11]}$ there is little relevant theoretically based research. This is problematic, as primary care is an increasingly complex environment, where multi-morbidity ${ }^{[12]}$ and multi-disciplinary care ${ }^{[13]}$ have become common for older patients. Appropriately chosen theoretical frameworks can facilitate conceptualisation of complex systems, the design of interventions, prediction of expected outcomes and their evaluation..$^{[1,15]}$ Thus, testing theoretical frameworks within which to design and evaluate interventions to improve patient acceptance of trainees has become necessary.

One potentially valuable framework for this field is agency theory. Agency relationships are said to exist when one person (an agent) is engaged by another (a principal) to act on the principal's behalf. ${ }^{[16-18]}$ In agency theory, it is held that risks arise when there is a significant divergence of goals or a lack of shared information between principals (in this case patients) and their agents (here doctors). ${ }^{[17]}$ In the literature this is termed 'agency loss', ${ }^{[16]}$ which in turn generates 'agency costs' to rectify. ${ }^{[17]}$ Classically, agency theorists address the management of agency loss (or costs) through mechanisms such as monitoring, contracts or incentive payments. ${ }^{[16,17]}$ However, it has long been recognised that medicine poses particular agency considerations because of the inherent roles of risk and trust in health professional-patient relationships. ${ }^{[19,20]}$ Aware of the interpersonal rather than contractual nature of healthcare relationships, continuity of care has been examined from an agency perspective and conceptualised as a mechanism that is used by patients to minimise agency loss in their healthcare. ${ }^{[16]}$ While this is a relatively novel approach, an agency theory construction of continuity has been demonstrated to have utility as a framework in chronic disease management research. ${ }^{[13,21]}$ Thus, agency theory may have value as a framework for exploration of patients' responses to trainees, particularly for chronic conditions. In this framework, patients with poor health, complex needs or lengthy medical histories may recognise increased 'costs' arising from the agency loss from seeing a trainee rather than their usual GP. This recognition of increased 'cost' may then be associated with reluctance to see a trainee or reduced satisfaction with trainee consultations. Figure 1 outlines these hypothesised predictors and outcomes in patient attitudes and behaviours towards trainees in an agency theory framework.

A large survey of older patients' attitudes to general practice trainees has recently been undertaken in Australia. ${ }^{[9]}$ This paper describes an exploratory factor analysis of the results from that study. Development of the survey instrument;

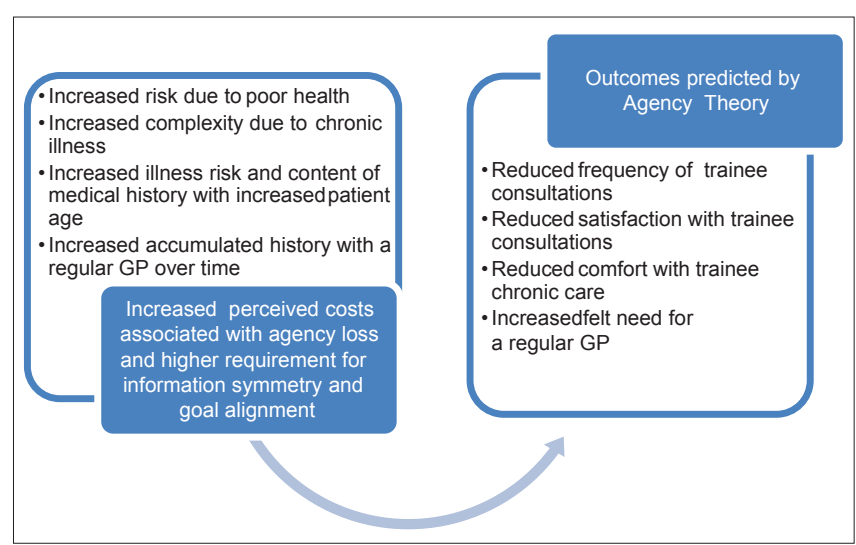

Figure 1: Hypothesised predictors and outcomes in patient attitudes and behaviours towards trainees in an agency theory framework

study design; participant recruitment; and results have been described in detail elsewhere. ${ }^{[9,22]}$ Preliminary exploration of the psychometric properties of the instrument during development suggested that the constructs of Interpersonal Continuity (IPC), Interpersonal Trust (IPT) and Institution/system Trust (ST) were underlying patients' responses to the survey questions. ${ }^{[2]}$ However, these pilot results were derived from a small sample from a geographically limited population..$^{[8,22]}$

Thus, this present study was designed to answer three research questions: (1) are the constructs (factors) underlying patients' responses stable across a broader population; (2) are the strengths with which patients express these constructs associated with patients' behaviours and attitudes and (3) does agency theory show potential as an explanatory framework for patients' behaviours and attitudes? The implications for practice and research regarding interventions designed to improve older patient-trainee interactions are discussed.

\section{Methods}

\section{Materials}

The development of the instrument was informed by a review of the literature, ${ }^{[11]}$ a qualitative study, ${ }^{[7]}$ a pilot survey ${ }^{[8]}$ and an exploratory factor analysis of the pilot study data. ${ }^{[22]}$ In addition to the 22 -item attitude scale, the instrument consisted of: Eight categorical items addressing the patient's demographics and pattern of use of GP services; a 5-point self-assessed patient health rating item; two satisfaction rating items (regarding trainee care and communication); and a 6-item chronic/complex condition management vignette. The attitude scale and vignette items used 5-point Likert response formats. The instrument was designed for self-completion by respondents.

\section{Study Design}

Approval was obtained from the Human Research Ethics Committee of the University of Wollongong. GP training in 
[Downloaded free from http://www.educationforhealth.net on Thursday, June 12, 2014, IP: 130.130.37.85] || Click here to download free Android application for this journal

Bonney, et al.: Trust, continuity and agency: Older patients and general practice trainees

Australia is decentralised. Training is undertaken in over 2500 private practices, co-ordinated geographically by 17 Regional Training Providers (RTPs) nationally at the time of the study. A stratified, randomised sample of 38 training practices was recruited from five RTPs (one from each of five Australian states), with the stratification intended to provide equal numbers of rural and non-rural practices [Figure 2].

In each participating practice, personnel were instructed to offer an information sheet and the questionnaire to 50 sequential patients aged 60 and over after their consultation. Distribution was undertaken during November and December 2009. The respondents returned completed questionnaires by mail to the university via stamped, self-addressed envelopes.

\section{Statistical Analyses}

The data were analysed using SPSS version 17 (IBM, New York, USA) software after checking for missing values and data entry errors. Questionnaires with missing age data were excluded from the study. The internal consistency of the attitude scale and the chronic disease management vignette were assessed using Cronbach's $\alpha$. The inter-item and item-total correlations were calculated for the attitude scale and examined for any items that substantially lowered the internal consistency or were redundant. Velicer's minimum average partial (MAP) test was used to determine the optimal number of factors to extract from the attitude scale, as it is considered more accurate than traditional rule-of-thumb approaches such as using Eigen values ${ }^{[23]}$ On theoretical grounds it was expected that the factors may be related; therefore, factor analysis

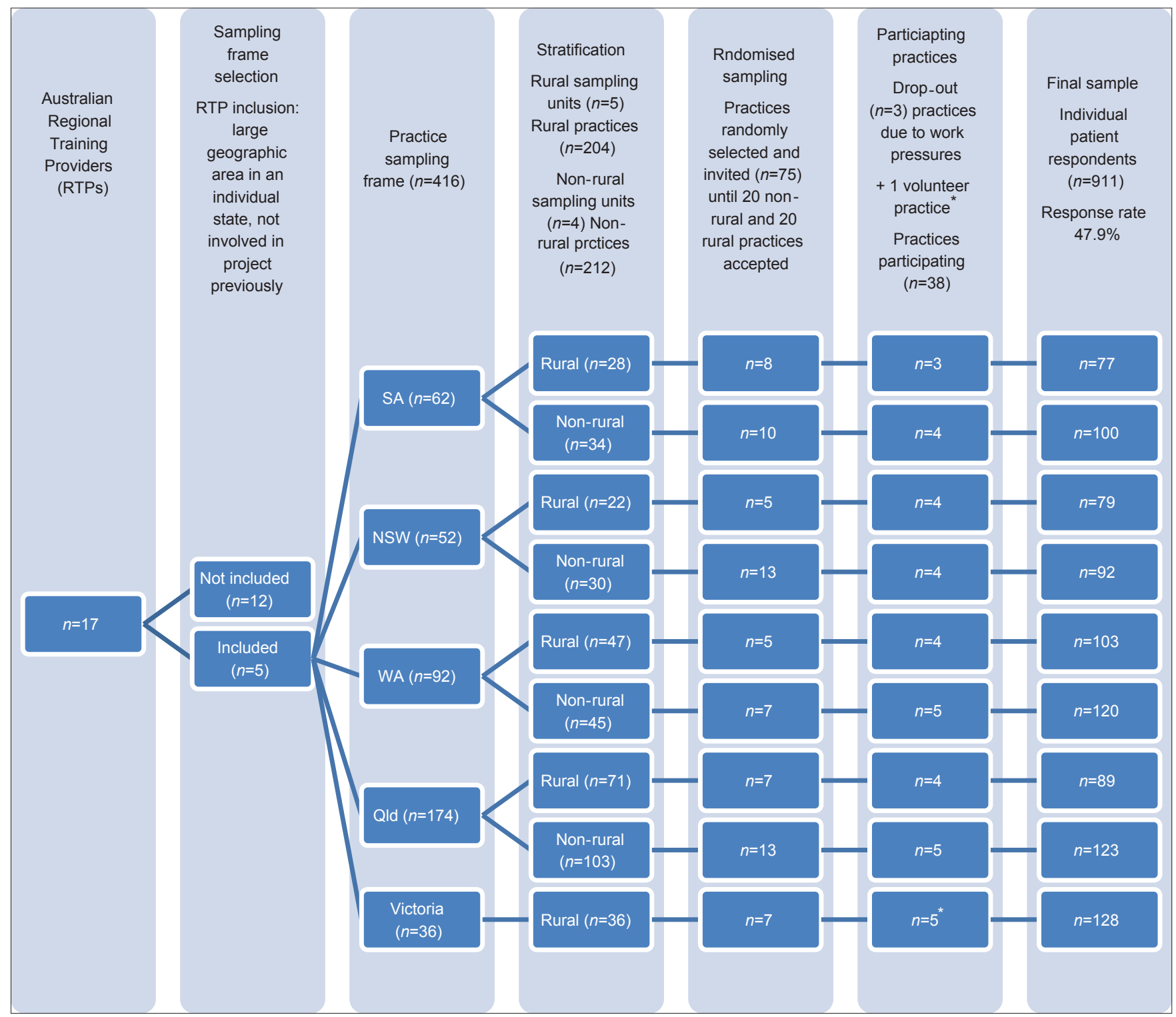

Figure 2: Study design flow diagram. RTP=Regional Training Provider, SA=South Australia, NSW=New South Wales, WA=Western Australia, QId=Queensland 
[Downloaded free from http://www.educationforhealth.net on Thursday, June 12, 2014, IP: 130.130.37.85] || Click here to download free Android application for this journal

Bonney, et al:: Trust, continuity and agency: Older patients and general practice trainees

was performed using Principal Component Analysis with Direct Oblimin Rotation to identify the factor structure and loadings. The respondents' scores for the items in each of the factors (subscales) identified were averaged.

The generalised estimating equations procedure in SPSS was used for binary logistic modelling to identify relationships between participant characteristics and behaviours, attitude items, vignette items and factor scores. Participants' state, rurality and practice were entered as subject variables into each of the models, reflecting the study design and controlling for the effects of intra-strata and intra-cluster correlations. To aid interpretation of the analyses, responses were collapsed into two groups to undertake the regressions such that a neutral response favoured the null hypothesis in Likert response format items, and a value of 4.0 or more was considered high for mean factor scores and self-rated health (SRH) scores. High $(>4.0)$ or low $(<4.0)$ scores for each of the three factor subscales were used as dependent variables for initial investigation. Models were tested for the dependent variables including as explanatory variables participant demographics (age and gender) and factors associated with the extent to which patients valued continuity of care derived from previous research (length of time with current GP, chronic illness and SRH). ${ }^{[10]}$ Models were then tested with factor subscale scores as explanatory variables. Dependent variables in these models were satisfaction with trainees, comfort with trainee chronic/complex care, frequency of trainee visits and feeling the need for a regular GP.

\section{Results}

\section{Sample Description}

Thirty-seven practices returned questionnaires: 19 rural and 18 non-rural. Of the 1900 distributed, 911 completed questionnaires (47.9\%) were returned. Response rates from the practices returning surveys ranged from $18 \%$ to $76 \%$ with a median of $44 \%$. Rural respondents comprised $52.2 \%$ of the sample. Characteristics of the sample are outlined in Table 1.

\section{Psychometric Properties of the Questionnaire}

Internal reliability was shown to be satisfactory for the 22 attitude items (Cronbach's $\alpha=0.79$ ). ${ }^{[24,25]}$ Deletion of individual items altered the baseline $\alpha$ a maximum of $+/-0.02$ (0.77-0.81). The range of inter-item correlation co-efficients was - 0.24 to 0.63 , with a mean of 0.15 . Item-total correlation co-efficients ranged from -0.05 to 0.58 with a mean of 0.34 . These results indicated that none of the items substantially reduced the internal consistency, overlapped considerably or were redundant. Hence, all 22 items were included in the subsequent factor analysis.

Three factors were extracted based on the results of Velicer's MAP test. Factor 1was comprised of items relating to

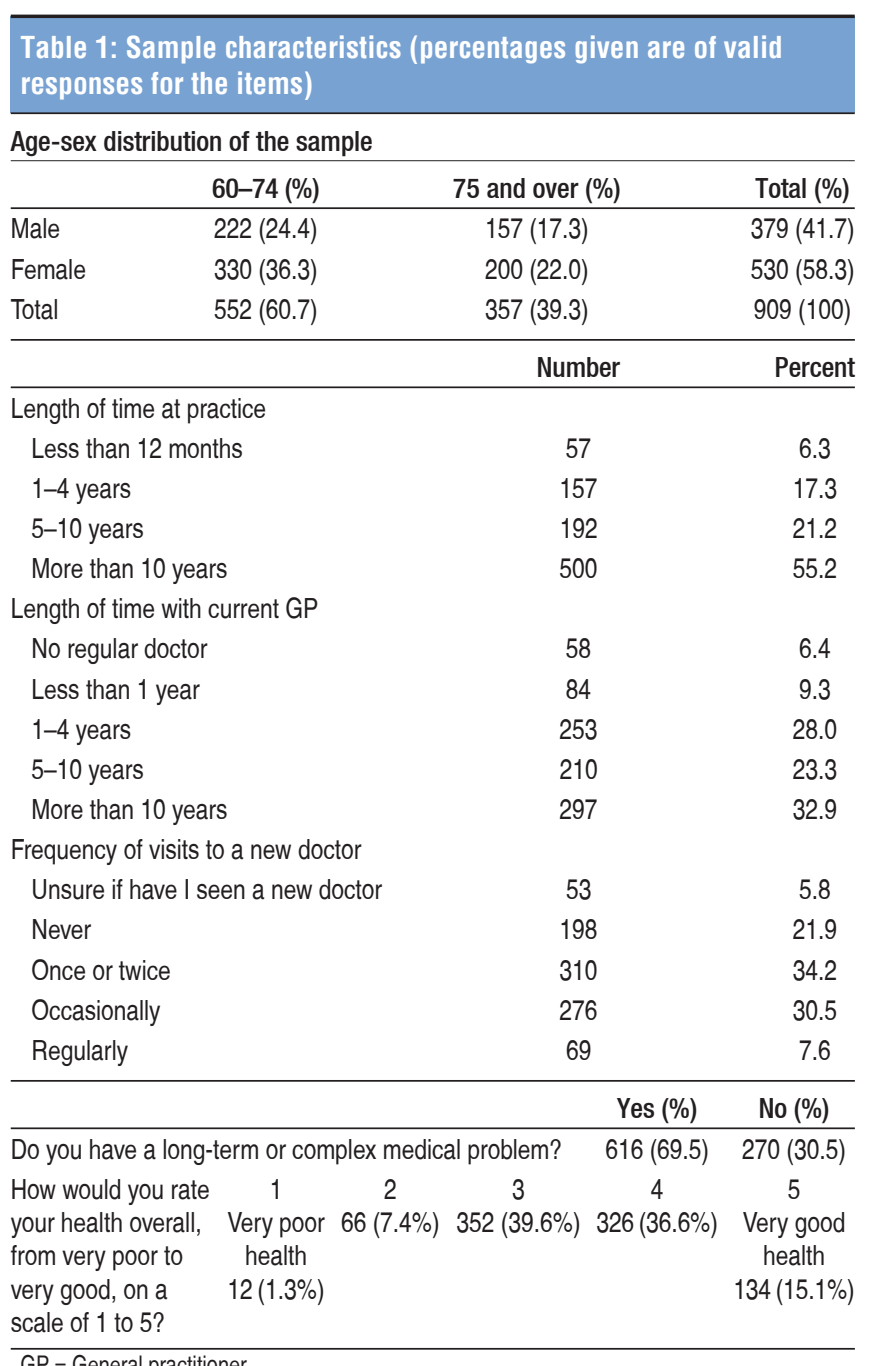

GP $=$ General practitioner

vulnerability in the anticipation of seeing a new doctor, in the context of an established relationship with a regular doctor, and was labelled 'Interpersonal Trust'. ${ }^{[26,27]}$ In the items in Factor 2 patients expressed a willingness to consult doctors in their clinic other than their regular GP, trust in the clinic they attended, or trust in doctors in general. It was labelled 'Institution/system Trust'. ${ }^{[26,28,29]}$ The third factor contained items referring to ongoing personal contact with the one GP. Hence it was labelled 'Interpersonal Continuity'. ${ }^{[30]}$ Two items extracted to IPT cross-loaded on IPC: Items 21 and 22. These items were extracted to IPC in the pilot study. We retained these items in IPT as: Their loadings were higher in IPT; the alpha for the respective subscales was reduced if the items were included in IPC; and face validity appeared stronger with the items in IPT. The items and their factor loadings are displayed in Table 2.

\section{Comparison with the Pilot Study}

Apart from the two items previously noted, the factor structure remained stable when tested across the two samples. The sub-scale alphas (IPT $\alpha=0.86$; Institution $/ \mathrm{ST} \alpha=0.70$ and IPC 
[Downloaded free from http://www.educationforhealth.net on Thursday, June 12, 2014, IP: 130.130.37.85] || Click here to download free Android application for this journal

$\alpha=0.75)$ were similar or improved compared with the pilot study results (IPT $\alpha=0.85$; Institution $/ \mathrm{ST} \alpha=0.71$ and IPC

\section{Table 2: Items arranged according to factor and factor loadings}

Item Item

no.

Factor 1 Interpersonal trust: Trust in a known physician based

primarily on personal experience and individual personalityy

9. I would not find seeing a new doctor reassuring 0.731

8. If I see a new doctor, I worry that they might not take $\quad 0.697$ my concerns seriously

6. I am uncertain how well a new doctor would be able to 0.692 help me with my problems

22. It takes time to develop a good relationship with a new 0.667 doctor

19. I don't like having to go through my medical history all 0.645 over again with a new doctor

5. In seeing a new doctor, it would take time to build trust $\quad 0.637$

7. I would not feel comfortable talking with one of the new 0.637 doctors about a sensitive problem

17. A new doctor would not have the full picture of my 0.603 medical history and background

11. It would be good to have information available regarding 0.603 the experience and qualifications of the new doctors

18. I am only willing to see a new doctor if I knew the doctor 0.588 worked closely with my regular doctor

12. It would be good to have information regarding what 0.508 period of time a new doctor will be working at my surgery (e.g. 6 months, 12 months, indefinitely)

21. If my usual doctor transferred my care to one of the new 0.499 doctors, l'd feel a bit abandoned

Factor 2 Institution/system trust: Trust in an individual clinic; or trust in clinics or the medical system as a whole. May be based on trust in a physician affiliated with a clinic; or trust in professional bodies, legal protections or media portrayals ${ }^{[26]}$

14. Supporting the new doctors who come to my medical practice might encourage more doctors to stay in the area

20. Knowing that my medical record is readily available helps me feel confident in seeing different doctors in the practice

13. I think my regular doctor is happy for me to see the new doctors for any of my medical problems

15. I expect that all of the doctors at the surgery I attend have good medical knowledge and skills

1. I am happy to see a new doctor for a minor medical complaint, or simple request like a repeat prescription

3. Most of the time it is more important for me to see any doctor who is available rather than waiting to see the doctor of my choice

Factor 3 Interpersonal continuity: An ongoing personal professional relationship between a patient and a physician characterized by patient trust and physician responsibility ${ }^{[30]}$

2. It is important to me to have a regular doctor who knows me and knows my medical history well

10. If I saw a new doctor for a medical problem, I would like to know that my ongoing contact with my regular doctor was not broken

4. I prefer to see my regular doctor for the management of all my medical conditions

16. The relationship I have with my usual doctor is something I would value continuing into the future

Only factor loadings $>0.400$ were retained, considered in analyses and displayed in Table 2

$\alpha=0.66)$. Similarly, the variance explained by each factor was comparable with that in the pilot study. In the present study IPT explained $25.6 \%$, Institution/ST $12.1 \%$ and IPC $8.2 \%$ of the variance compared with $26.2 \%, 11.4 \%$ and $7.5 \%$, respectively, in the pilot study. ${ }^{[2]}$

\section{The Factors and their Associations}

From the overall sample, IPT had a range of factor scores of 1.00-5.00 with a mean of 3.50 (SD 0.76) and 235 responses with scores of 4.0 or more. Higher scores were considered to indicate a higher requirement for an existing doctor-patient relationship to enable trust. Institution/ST had a range of factor scores of 1.00-5.00, mean 4.04 (SD 0.63) and 498 responses with scores 4.0 or more. Higher scores were considered to indicate a higher level of trust at a non-personal, institution or system level. Scores in IPC ranged from 1.75 to 5.00, mean 4.66 (SD 0.56 ) with 788 respondents with scores of 4.0 or more. In this factor, higher scores were considered to demonstrate a higher requirement for personal continuity of care with their GP.

\section{Table 3: Variables retained after logistic regression}

Odds
ratio $\frac{95 \% \mathrm{Cl}}{\text { Lower Upper }}$ Sig.

Variables predicting high Interpersonal trust score

Self-rated health score $\leq 3$ in a 5 -point scale

$\begin{array}{llll}1.46 & 1.05 & 2.03 & P=0.023\end{array}$

Female gender

Variables predicting high institution/system trust score

0.732

0.675

0.656

0.601

0.546

0.535

Age $\geq 75$ years

Self-rated health score $\geq 4$ in a 5 -point scale

Variables predicting high interpersonal continuity score

Female gender

Chronic illness

Being with current GP 5 or more years

Factor scores predicting satisfaction with GP trainees (score $\geq 4 / 5$ in 5 -point scale)

High interpersonal trust score

High institution/system trust score

Factor scores predicting comfort with GP trainee chronic/complex problem care

High interpersonal continuity score

High interpersonal trust score

High institution/system trust score

Factor scores predicting increased frequency of $-0.768 \quad$ GP trainee visits

High institution/system trust score

High interpersonal continuity score

Factor scores predicting feeling the need for a regular GP

High institution/system trust score

High interpersonal trust score

$\begin{array}{llll}1.85 & 1.34 & 2.57 & P<0.001\end{array}$

High interpersonal continuity score

$\mathrm{GP}=$ General practitioner; $\mathrm{Cl}=$ Confidence interval 
[Downloaded free from http://www.educationforhealth.net on Thursday, June 12, 2014, IP: 130.130.37.85] || Click here to download free Android application for this journal

Binary logistic regression was undertaken on the overall sample. Of note, participants with lower SRH scores were significantly more likely to have high IPT scores $(P=0.023)$; those with higher SRH scores were significantly more likely to have high Institution/ST scores $(P=0.001)$; while those with chronic illnesses were significantly more likely to have high IPC scores $(P=0.005)$. Factor scores were then used as independent variables in regression models, to assess their associations with selected attitudes and behaviours. Participants with high Institution/ST scores were significantly more likely to have a higher frequency of trainee visits $(P<0.001)$, feel comfortable with trainee chronic problem care $(P<0.001)$ and be satisfied with trainee consultations $(P<0.001)$. They were also significantly less likely to feel the need for a regular GP $(P=0.003)$. In contrast, participants with high IPC scores were significantly less likely to feel comfortable with trainee chronic problem care $(P<0.001)$ and those with high IPT scores less likely to be satisfied with trainee consultations $(P=0.001)$. All variables retained after logistic regression are presented in Table 3.

\section{Discussion}

\section{The Results in Relation to the Research Aims}

These findings suggest that the constructs underlying older patients' attitudes towards GP trainees in Australia were stable across geographically diverse populations. The strength with which these constructs were expressed was associated with a range of attitudes and behaviours towards trainees. The findings overall were consistent with an agency theory framework. Eighty-six percent $(n=788)$ of the 911 older patients surveyed in the training practices in this study had high factor scores for IPC, consistent with patients seeking to reduce risks associated with agency loss by maintaining continuity with their regular GP. In addition, the hypothesised predictors and outcomes in an agency framework were largely upheld. However, the use of the IPC, Institution/ST and IPT constructs as variables in the statistical models provided a more detailed picture than that initially hypothesised. Figure 3 displays a visual model of the findings.

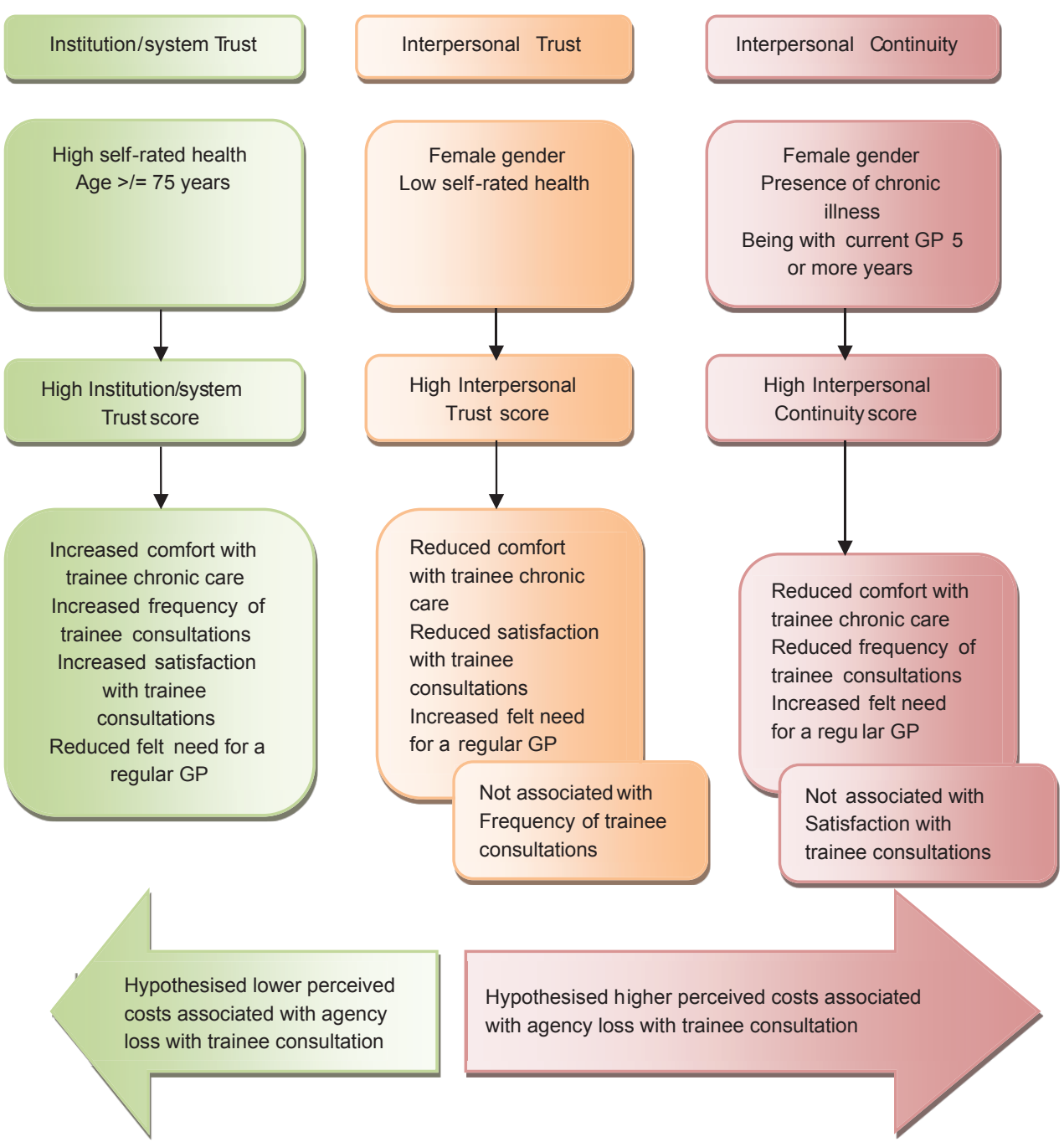

Figure 3: Model of predictors and outcomes in patient attitudes and behaviours towards trainees 
[Downloaded free from http://www.educationforhealth.net on Thursday, June 12, 2014, IP: 130.130.37.85] || Click here to download free Android application for this journal

\section{Results in Relation to Agency Theory and Previous Research}

There is a paucity of literature relating patients' attitudes in GP training facilities to a proposed theoretical framework. Our findings have support in previous research concerning trust $^{[26,28,31]}$ and continuity of care. ${ }^{[10,32,33]}$ Of interest, our findings suggest a continuum of patient attitudes and behaviours regarding trainees, ranging from positive attitudes and attendance patterns associated with high Institution/ST score; through reduced satisfaction and comfort associated with high IPT score; to reduced attendance and further reduction in comfort associated with high IPC score. These associations were mirrored by the results relating to the perceived need for a regular GP as a dependent variable. The need for a regular GP was reduced in association with high Institution/ST score; positively associated with IPT score; and even more strongly associated with high IPC score. It was notable that poor SRH was associated with high IPT score and not high IPC score. At the same time, presence of a chronic condition was associated with high IPC but not high IPT scores. In keeping with the literature, we propose that poor SRH contributes to a sense of vulnerability; ${ }^{[20,26,33]}$ hence its association with an increased need for IPT and reduced satisfaction with visits to other than the trusted regular GP. This dynamic may occur independently of the associations of presence of a chronic condition, preference for IPC and reduced trainee visits; as a chronic condition may not be associated with perceived poor health and vulnerability (e.g. uncomplicated hypertension or diabetes), but will require more planned visits with a regular GP. Patients may be satisfied with trainee visits in this instance, particularly if convenient. ${ }^{[7,9]}$ However, this requires further research, along with investigating the reasons for the positive associations of age and female gender with Institution/ST and IPT/IPC, respectively.

\section{Limitations of this Study}

The previously noted limitations concerning this sample should be borne in mind when generalising these results. ${ }^{[9]}$ The participant response rate was $47.9 \%$ and it was not possible to track non-responders. Hence, it is not known whether there was a systematic difference between the participating and non-participating groups. A further potential weakness is that while indicating the widespread requirement for continuity, the IPC subscale demonstrated low discriminating power, as indicated by its high mean factor score (4.66) and accounting for just $8.2 \%$ of the variance. While there is support in the literature for our conclusions, they should be considered hypothesis generating until data from prospective studies and international comparisons are available.

\section{Implications for Practice and Further Research}

In agency theory terms, the goal of enhanced trainee chronic disease management is best approached by seeking to optimise information symmetry and goal alignment between older patients and their healthcare team. An example of how this might be brought about is a structured chronic disease clinic where the GP supervisor briefly joined the consultation between a patient and a trainee, enhancing information and goal sharing. This could be thought of in terms of meeting the needs for interpersonal trust and continuity. Other examples include providing information concerning the experience and qualifications of trainees and making explicit the supervision provisions in place, thus improving information symmetry. ${ }^{[7,8,34]}$ This could be seen as enhancing institution trust in the facility. Formal trials of such strategies are desirable, with assessment of information symmetry and goal alignment as key variables in an agency theory-driven evaluation framework.

\section{Conclusions}

The constructs identified in this study appear stable across Australian populations and are associated with older patients' attitudes and behaviours. These empirical findings are consistent with agency theory and raise further questions for research. An agency theory framework for models of care in training practices warrants further research and shows potential for designing and evaluating interventions to improve patient acceptance of trainees as the population ages.

\section{References}

1. UN. World Population Ageing: 1950-2050. 2001. Available from: http://www.un.org/esa/population/publications/ worldageing 19502050/pdf/62 executivesummary_english. pdf [Last accessed on 2012 Nov 11].

2. WHO. Global status report on noncommunicable diseases 2010. 2011. Available from: http://whqlibdoc.who.int/ publications/2011/9789240686458_eng.pdf [Last accessed on 2012 Nov 11].

3. Harris MF, Zwar NA. Care of patients with chronic disease: the challenge for general practice. Med J Aust 2007;187:104-7.

4. NHHRC. A Healthier future for all Australians-final report of the National Health and Hospitals Reform Commission-June 2009. Available from: http://www.health.gov.au/internet/nhhrc/publishing. nsf/Content/nhhrc-report [Last accessed on 2010 Sep 28].

5. WHO. Towards age-friendly primary health care. 2004. Available from: http://whqlibdoc.who.int/publications/2004/9241592184. pdf. [Last accessed on 2012 Nov 11].

6. Spike N, Britt H. The clinical activities of VMA Registrars in each stage of training. Final report to Victoria Metropolitan Alliance. Melbourne: Monash University; 2006.

7. Bonney A, Phillipson L, Jones SC, Iverson D. Older patients' attitudes to general practice registrars-A qualitative study. Aust Fam Physician 2009;38:927-31.

8. Bonney A, Jones SC, Phillipson L, Iverson D. General practice registrars: Attitudes of older patients. Aust Fam Physician 2010;39:419-24.

9. Bonney A, Jones SC, Iverson D. The older patient, the general practitioner and the trainee: Patients' attitudes and implications for training. Educ Prim Care 2012;23:186-95.

10. Nutting PA, Goodwin MA, Flocke SA, Zyzanski SJ, Stange KC. Continuity of primary care: To whom does it matter and when? Ann Fam Med 2003;1:149-55. 
[Downloaded free from http://www.educationforhealth.net on Thursday, June 12, 2014, IP: 130.130.37.85] || Click here to download free Android application for this journal

11. Bonney A, Phillipson L, Reis S, Jones SC, Iverson D. Patients' attitudes to general practice registrars: A review of the literature. Educ Prim Care 2009;20:371-8.

12. Britt HC, Harrison CM, Miller GC, Knox SA. Prevalence and patterns of multimorbidity in Australia. Med J Aust 2008;189:72-7.

13. Bonney A, Magee C, Pearson R. Cross-sectional survey of older patients' views regarding multidisciplinary care for chronic conditions in general practice. Aust J Prim Health 2012;20:27-33.

14. Luca NR, Suggs LS. Theory and model use in social marketing health interventions. J Health Commun 2012;18:20-40.

15. Pawson R, Greenhalgh T, Harvey G, Walshe K. Realist review-a new method of systematic review designed for complex policy interventions. J Health Serv Res Policy 2005;10 Suppl 1:21-34.

16. Donaldson MS. Continuity of care: A reconceptualization. Med Care Res Rev 2001;58:255-90.

17. Shapiro SP. Agency theory. Annu Rev Sociol 2005;31:263-84.

18. Eisenhardt KM. Agency Theory: An assessment and review. Acad Manage Rev 1989;14:57-74.

19. Arrow KJ. Uncertainty and the welfare economics of medical care. Am Econ Rev 1963;53:941-73.

20. Hall MA. Arrow on trust. J Health Polit Policy Law 2001;26:1131-44.

21. Wei X, Barnsley J, Zakus D, Cockerill R, Glazier R, Sun X. Assessing continuity of care in a community diabetes program: Initial questionnaire development and validation. J Clin Epidemiol 2008;61:925-31.

22. Bonney A, Magee C, Caputi P. Measuring older patients' attitudes to general practice registrars: Exploratory factor analysis of a survey instrument. Focus Health Prof Educ 2011;12:74-85.

23. O'Connor BP. SPSS and SAS programs for determining the number of components using parallel analysis and velicer's MAP test. Behav Res Methods Instrum Comput 2000;32:396-402.

24. Bland JM, Altman DG. Cronbach's alpha. Br Med J 1997;314:572.
25. Schmitt N. Uses and abuses of coefficient alpha. Psychol Assess 1996;8:350-3.

26. Hall MA, Dugan E, Zheng B, Mishra AK. Trust in physicians and medical institutions: What is it, can it be measured, and does it matter? Milbank Q 2001;79:613-39, v.

27. Hall MA, Zheng B, Dugan E, Camacho F, Kidd KE, Mishra A, et al. Measuring patients' trust in their primary care providers. Med Care Res Rev 2002;59:293-318

28. Bonds DE, Foley KL, Dugan E, Hall MA. An exploration of Patients' Trust in Physicians in Training. J Health Care Poor Underserved 2004; 15:294-306.

29. Rowe R, Calnan M. Trust relations in health care: Developing a theoretical framework for the "new" NHS. J Health Organ Manag 2006;20:376-96.

30. Saultz JW. Defining and measuring interpersonal continuity of care. Ann Fam Med 2003;1:134-43.

31. Mechanic D. The functions and limitations of trust in the provision of medical care. J Health Polit Policy Law 1998;23:661-86.

32. von Bultzingslowen I, Eliasson G, Sarvimaki A, Mattsson B, Hjortdahl P. Patients' views on interpersonal continuity in primary care: A sense of security based on four core foundations. Fam Pract 2006;23:210-9.

33. Frederiksen HB, Kragstrup J, Dehlholm-Lambertsen B. Attachment in the doctor-patient relationship in general practice: A qualitative study. Scand J Prim Health Care 2010;28:185-90.

34. Reichgott MJ, Schwartz JS. Acceptance by private patients of resident involvement in their outpatient care. J Med Educ 1983;58:703-9.

How to cite this article: Bonney A, Jones SC, Iverson D, Magee C. Trust, continuity and agency: Keys to understanding older patients' attitudes to genera practice trainees. Educ Health 2014;27:39-46.

Source of Support: This research was supported in part by a grant from Coast City Country GP Training Conflict of Interest: No. 